\title{
Asthma control and action plans
}

\author{
To the Editor:
}

Kouri et al. [1] in Canada have developed a tool to guide completion of asthma action plans (AAPs). In their rationale, they suggest that "fewer than $25 \%$ of patients receive an AAP, partly due to prescribers' inability to complete 'yellow zone' instructions (how to intensify therapy for acute loss of control)". The authors "reviewed recent asthma guidelines and adult studies addressing acute loss of asthma control" and "developed evidence-based rules for yellow zone therapy and operational guidelines to maximise adherence and minimise errors".

There is a substantial inherent flaw in this study, both in its rationale and methodology. The authors suggested that completing yellow-zone instructions equates with advice regarding how to intensify therapy for acute loss of control.

It is generally accepted that AAPs should be patient- and future-oriented, and designed for action to be taken when there is an acute exacerbation characterised by an increase in symptoms. The concept of asthma control is now well established and is defined by many authorities $[2,3]$ as "the extent to which the manifestations of asthma are controlled, with or without treatment" [2]. The 2015 Global Initiative for Asthma (GINA) strategy recommends that assessment of asthma control should be appreciated in two main domains with respect to impairment of quality of life (i.e. symptoms/limitation) and future risk [2] with regard to assessment of symptom control over the last 4 weeks and assessment of risk factors for poor outcomes, including reduced lung function. GINA recommends that both components (symptom control and future risk) should be monitored by the physicians at each clinic visit.

Thus, in sharp contrast to AAPs, asthma control is a retrospective assessment and is healthcare provider oriented. KOURI et al. [1] appear to represent the relatively recent Canadian approach, which unfortunately includes the control concept within the AAP. Consequently, there is a substantial difference in the advice that may be given to caregivers as to how to respond to an acute exacerbation using the AAP yellow-zone instructions. The goals of AAPs in Canada are defined as "Action plans outline strategies to achieve and maintain control, when and how to adjust reliever and controller therapy in a response to acute loss of asthma control" [4].

In contrast to most other AAPs, which do not refer to short-lived exacerbations as "loss of control", the Canadian AAPs include the term "loss of control". To confuse matters further, the Canadian AAPs emphasise the problem by using the term "acute loss of control". Given that control of asthma, by definition, includes assessment of symptom control over the last 4 weeks and risk factors for poor outcomes, including abnormal lung function [2], there cannot be a notion that incorporates a concept such as acute loss of control without causing considerable confusion in the minds of both healthcare professionals and patients.

Thus, the use of the term "acute loss of control" is clearly inappropriate. None of the US, British, Australian or European guidelines use this term. The inclusion of this idea by Kouri et al. [1] is likely to result in considerable confusion and poor compliance.

Moreover, the current tool was said to have been developed after a systematic search that included "all RCTs, reviews and systematic reviews that described strategies for adjusting controller therapy for acute loss of asthma control in adults with persistent asthma on regular maintenance therapy". The authors included almost 200 key terms in their search strategy of three databases (appendix 3 of their article). However, none of these terms included the words "acute loss of asthma control" or even "loss of asthma control".

@ERSpublications

Asthma action plans should not cause confusion for patients by incorporating the concept of "acute loss of control" http://ow.ly/nY1R30fDFC6

Cite this article as: Amirav I, Newhouse MT. Asthma control and action plans. Eur Respir J 2017; 50: 1701640 [https://doi.org/10.1183/13993003.01640-2017]. 
Moreover, among the 11 studies included in this paper, only one study specifically addressed the term "acute loss of control". None of the other 10 included this term. It is of interest that while this single article was referenced in the Canadian Thoracic Society guidelines, it was not referred to in any other international guidelines.

Questions in a systematic review should be stated precisely and explicitly so that readers can quickly understand the scope of the review and the potential applicability of the review to their interests [5]. We are not aware of any systematic review methodology that searches the literature with one set of Medical Subject Headings while using totally different terms in the resulting conclusions.

We believe, as in most AAPs internationally, that there is no evidence to support combining, in an AAP, instructions for the self-management of transient acute exacerbations with advice regarding the treatment of poorly controlled asthma. It is our opinion and clearly that of all other well-known guidelines that combining these two concepts in an AAP might be extremely difficult for patients to comprehend and may lead to considerable confusion. We would suggest that the Canadian AAPs be revised and the "control of asthma" concept be returned to the professional caregiver's care.

Israel Amirav $\oplus^{1}$ and Michael T. Newhouse ${ }^{2}$

${ }^{1}$ Dept of Pediatrics, University of Alberta, Edmonton, AB, Canada. ${ }^{2}$ Firestone Institute for Respiratory Health, St Joseph's Hospital, McMaster University, Hamilton, ON, Canada.

Correspondence: Israel Amirav, Dept of Pediatrics, University of Alberta, 1801 11135-83 Ave, Edmonton T6G 2C6, AB, Canada. E-mail: amirav@ualberta.ca

Received: Aug 112017 | Accepted: Sept 052017

Conflict of interest: None declared.

\section{References}

1 Kouri A, Boulet LP, Kaplan A, et al. An evidence-based, point-of-care tool to guide completion of asthma action plans in practice. Eur Respir J 2017; 49: 1602238.

2 Global Initiative for Asthma. Global Strategy for Asthma Management and Prevention. Updated 2015. http:// ginasthma.org/wp-content/uploads/2016/01/GINA_Report_2015_Aug11-1.pdf Date last updated: 2015.

3 Dinakar C, Chipps BE. Clinical tools to assess asthma control in children. Pediatrics 2016; 139: e20163438.

4 Lougheed MD, Leniere C, Ducharme FM, et al. Canadian Thoracic Society 2012 guideline update: diagnosis and management of asthma in preschoolers, children and adults: executive summary. Can Respir J 2012; 19: e81-e88.

5 Liberati A, Altman DG, Tetzlaff J, et al. The PRISMA statement for reporting systematic reviews and meta-analyses of studies that evaluate healthcare interventions: explanation and elaboration. BMJ 2009; 339: b2700.

Copyright @ERS 2017

From the authors:

We would like to thank I. Amirav and M.T. Newhouse for their correspondence in response to our recent paper, "An evidence-based, point-of-care tool to guide completion of asthma action plans in practice" [1]. They raise an important issue surrounding confusion between the concepts of poor baseline asthma control and acute changes in symptoms that merit activation of the "yellow zone" of the asthma action plan (AAP). Although, contrary to their contention, this discussion does not affect the objective or outcome of our analysis, which was to provide a practical, evidence-based guide to populating the AAP yellow zone, it merits further discussion.

I. Amirav and M.T. Newhouse argue that the expression "acute loss of asthma control", used in Canadian guidelines and in our paper, should not be used in the context of an AAP. They raise a concern that this terminology may be confused by patients and clinicians to be a measure of baseline asthma control, which is a different concept, requiring periodic determination by healthcare providers through both a retrospective assessment of symptoms and an understanding of risk factors for poor outcomes. We agree that these are distinct concepts that are often confused by practitioners. However, these authors fail to

@ERSpublications

Arguments over semantics will not advance our common goal of improving AAP uptake http://ow.ly/rSaq30fRila

Cite this article as: Kouri A, Boulet L-P, Kaplan A, et al. Asthma control and action plans. Eur Respir J 2017; 50: 1701883 [https://doi.org/10.1183/13993003.01883-2017]. 
recognise that the reason for confusion between poor control at baseline and acute loss of control in an AAP is not simply due to use of the phrase "acute loss of asthma control" but rather because the thresholds used to describe these states are often identical. Our comprehensive review of 69 AAPs used in randomised controlled trials (RCTs) and by asthma programmes around the world demonstrated that thresholds for the first action point in AAPs (usually called the yellow zone) were often based on the same thresholds that guidelines have defined for baseline control [2]. These included the frequency of daytime symptoms, night-time symptoms, rescue bronchodilator use, absenteeism and exercise limitation. Given that there is no objective evidence for what should constitute an appropriate threshold for acute worsening that merits a transient escalation in therapy, historically, authors appropriated baseline control thresholds in the original AAPs that were tested in RCTs, and these criteria became entrenched after initial studies showed beneficial effects of those AAPs. Thus, although acute worsening requiring transient escalation in therapy and generalised poor control requiring escalation in baseline therapy are distinct management concepts, the thresholds used to define them overlap significantly.

Authors also imply that Canadian guidelines "support combining, in an AAP, instructions for the self-management of transient acute exacerbations with advice regarding the treatment of poorly controlled asthma". Rather, Canadian guidelines, like all other international guidelines, consider and provide explanations and recommendations for these concepts separately and distinctly. Furthermore, contrary to the authors' contention that "none of the US, British, Australian or European guidelines use this term", the "control" descriptor for AAPs is not only used by Canadian guidelines, but by the latest British and US asthma guidelines, and the Global Initiative for Asthma (GINA) strategy document. British (British Thoracic Society/Scottish Intercollegiate Guidelines Network) guidelines describe the content of AAPs as "specific advice about recognising loss of asthma control, assessed by symptoms or peak flows or both" and emphasise the importance of AAPs "so that the patient is aware of the action to take if their control deteriorates" [3], the US (National Heart, Blood and Lung Institute) guidelines recommend that AAPs "encompass instructions both for daily actions to keep asthma controlled and for actions to adjust treatment when symptoms or exacerbations occur" [4] and the GINA strategy recommends that controller medication should be increased as part of an AAP "when there is a clinically important change in the patient's usual level of asthma control" [5].

We also note that there "is no international consensus of the best terms to use to describe worsening asthma", according to the Cochrane Airways Group editorial board, and contrary to what I. Amirav and M.T. Newhouse claim [6]. Like the international asthma guideline groups cited above, our author group of clinical respirologists and primary care physicians believes that our intended audience of primary care physicians would understand that "acute loss of asthma control" is synonymous with "acute asthma worsening" or "transient acute exacerbation." Communication of these concepts to patients should of course be individualised to each patient's needs and level of understanding.

Despite overwhelming evidence for their benefit and consistent international guideline recommendations for their use for over 20 years now, AAPs are seldom used in practice. I. Amirav and M.T. Newhouse's contention that use of the "control" terminology contributes to this "poor compliance" with AAPs is unfounded, and ignores robust literature on the actual barriers and enablers to AAP use [7]. Barriers exist at the level of providers, the practice environment and the overall healthcare system. By developing an evidence-based, point-of-care tool providing guidance on AAP yellow-zone formulation, we sought to address a well-described clinician knowledge barrier.

Unsupported arguments focusing on semantics miss the forest for the trees and will not advance our common goal of improving AAP uptake. Although we fully acknowledge that other barriers, including clinician time, patient-clinician communication and point-of-care availability, must also be addressed, we believe that addressing knowledge was an important first step. We entreat all of our colleagues in the respiratory community to rise to this important implementation challenge.

Andrew Kouri ${ }^{1}$, Louis-Philippe Boulet ${ }^{2}$, Alan Kaplan ${ }^{3}$ and Samir Gupta ${ }^{1,4}$

${ }^{1}$ Dept of Medicine, Division of Respirology, University of Toronto, Toronto, ON, Canada. ${ }^{2}$ Institut universitaire de cardiologie et de pneumologie de Québec, Université Laval, Québec, QC, Canada. ${ }^{3}$ Family Physician Airways Group of Canada, University of Toronto, Toronto, ON, Canada. ${ }^{4}$ The Keenan Research Centre in the Li Ka Shing Knowledge Institute of St Michael's Hospital, Toronto, ON, Canada.

Correspondence: Andrew Kouri, Division of Respirology, 1 King's College Circle, 6263 Medical Sciences Building, Toronto, ON, M5S 1A8, Canada. E-mail: andrew.kouri@mail.utoronto.ca

Received: Sept 152017 | Accepted: Sept 182017

Conflict of interest: None declared. 


\section{References}

1 Kouri A, Boulet LP, Kaplan A, et al. An evidence-based, point-of-care tool to guide completion of asthma action plans in practice. Eur Respir J 2017; 49: 1602238.

2 Gupta S, Wan FT, Ducharme FM, et al. Asthma action plans are highly variable and do not conform to best visual design practices. Ann Allergy Asthma Immunol 2012; 108: 260-265.e2.

3 British Thoracic Society/Scottish Intercollegiate Guidelines Network. British guideline on the management of asthma: a national clinical guideline. www.brit-thoracic.org.uk/document-library/clinical-information/asthma/ btssign-asthma-guideline-2016/ Date last accessed: September, 2017.

4 National Heart, Lung and Blood Institute, National Asthma Education and Prevention Program. Guidelines for the diagnosis and management of asthma 2007. www.nhlbi.nih.gov/files/docs/guidelines/asthgdln.pdf Date last accessed: September, 2017.

5 Global Initiative for Asthma. Global strategy for asthma management and prevention. http://ginasthma.org/ 2017-gina-report-global-strategy-for-asthma-management-and-prevention/ Date last accessed: September, 2017.

6 Normansell R. How should we describe worsening asthma in Cochrane Reviews, and does it matter? Cochrane Database Syst Rev 2014; 11: ED000092.

7 Ring N, Jepson R, Hoskins G, et al. Understanding what helps or hinders asthma action plan use: a systematic review and synthesis of the qualitative literature. Patient Educ Couns 2011; 85: e131-e143. 